\title{
Meeting of Dreams
}

\section{Dana Mackenzie}

"If you build it, they will come." This quote, which has entered the lexicon thanks to the baseballthemed movie Field of Dreams, could also have been the motto for the Heidelberg Laureate Forum (HLF), which was held in the last week of September 2013. It was a "meeting of dreams" that brought the legends of computer science and mathematics together in one place for one week to hobnob with a younger generation of scientists who are just beginning their careers. Fortunately, unlike in the movie, the legendary greats did not have to come back from the dead.

The HLF was the brainchild of Klaus Tschira, the founder of the German software firm SAP and, through his Klaus Tschira Foundation, one of Europe's leading philanthropists. Like the movie's protagonist, Tschira organized his meeting of dreams in his metaphorical backyard: Heidelberg, home to one of the oldest universities in the world, whose cobblestoned beauty was relatively untouched by the wars of the twentieth century. (The wars of the seventeenth century are another matter. Heidelberg Castle, site of the closing banquet, was blown up by the French in 1689 and never fully rebuilt; it remains a picturesque ruin.)

Tschira conceived of the HLF as a counterpart to the Lindau Nobel Laureate Meeting, which has been held every year since 1951. Mathematics and computer science do not, of course, have a Nobel Prize, but Tschira thought that should not be an obstacle to getting the younger and older generations together. "I saw in Lindau how young physicists and chemists and biologists gained

Dana Mackenzie is a freelance mathematics and science writer who was invited to attend the Heidelberg Laureate Forum as an "official blogger". His posts as well as those of the other bloggers can be found at www.scilogs. com/hlf.

DOI: http://dx.doi.org/10.1090/noti1072 inspiration from meeting the Nobel laureates face to face, so I thought, why not do this for mathematics and computer science?" says Tschira.

In 2012 Tschira and Andreas Reuter, the Scientific Chairperson of the HLF, proposed the idea to the organizations that award the top prizes in mathematics and computer science: the Association for Computing Machinery (ACM), which administers the Turing Prize; the Norwegian Academy of Sciences and Letters, which awards the Abel Prize in mathematics; and the International Mathematics Union (IMU), which awards the Fields Medal in mathematics and the Nevanlinna Prize in information sciences. Without the enthusiastic support of all these organizations, "this forum would not have happened," said Tschira at the closing banquet.

The HLF committee contacted every living laureate of the four prizes and sent photographer Peter Badge around the world to take new studio-quality portraits of more than ninety of them. Poster-sized versions of Badge's portraits were displayed prominently in a public square of Heidelberg throughout the week of the meeting, giving mathematicians the rare illusion of being as important as politicians. (The first day of the HLF coincided with Germany's national elections, and the faces of the scientists competed with those of the candidates for public attention.)

So the stage was set; but would the laureates come? The answer from the computer scientists was a resounding yes, as thirty superstars of the subject made the pilgrimage to Heidelberg. They included Vint Cerf, the "chief Internet evangelist" at Google and designer of TCP/IP, the Internet communication protocol; Ronald Rivest, coinventor of the famous RSA public-key encryption system; Butler Lampson, who launched the personal computer from his famous laboratory at Xerox Palo Alto Research Center, and Alan Kay, who helped 
him do it; and Silvio Micali and Shafi Goldwasser, the lone female laureate, who developed a new cryptosystem based on zero-knowledge proofs.

The turnout on the mathematical side was much sparser. Only nine laureates of the Fields Medal and Abel Prize appeared in Heidelberg. The brave nine (just enough for a baseball team!) were Sir Michael Atiyah, Gerd Faltings, Curtis McMullen, Stephen Smale, Endre Szemeredi, Srinivasa Varadhan, Cedric Villani, Vladimir Voevodsky, and Efim Zelmanov. While the dividing line between mathematicians and computer scientists can be fuzzy (the Nevanlinna Prize winners and even some Turing Award winners could be counted in either group), Tschira did not mince words when expressing his disappointment. "Some may feel that there are not many mathematicians present here," he said during the opening ceremony. "Personally, I feel very sorry about this. It is even more deplorable because the jury admitted the same number of young researchers in each discipline." (One hundred young mathematicians and one hundred young computer scientists were selected to attend, out of approximately six hundred applicants.) If the purpose of the meeting was dialogue between the generations, the younger generation of mathematicians could be forgiven for inferring that the older generation did not want to talk with them.

Ingrid Daubechies, the current president of the IMU, agreed with Tschira that the disappearing act of the mathematics laureates was a great opportunity lost for mathematics. Not only did they miss a chance to inspire a new generation of mathematicians, they also missed the chance to reforge the links between mathematics and computer science. "For example, there is so much interaction today between mathematics and machine learning," Daubechies said. "People from geometry, topology, and a lot of different fields are working on ways to find structure in large data sets." The problem of "big data" cuts across all the sciences, and this would have been a chance for top-level mathematicians to engage themselves with it.

One can only speculate on the reasons why the mathematics laureates did not attend. The author of this piece believes that the forum organizers did not fully grasp the cultural differences between computer science and mathematics. The computer science laureates who attended the forum are more than mere colleagues-they are the people who invented the subject, from software to hardware to theory. As such, they are a much closer-knit group than the mathematics laureates. Juris Hartmanis, 1993 Turing Award laureate, pointed out that many of the computer scientists who came to the forum also attended the ACM meeting earlier this summer. By contrast, there is no one meeting that attracts a large proportion of the leading mathematicians. The International Congress of Mathematicians is the closest thing, but it occurs only once every four years. I believe the HLF Foundation needs to work closely with national or regional mathematics organizations as well as with the IMU. Fortunately, 2014 happens to be an "on" year for the International Congress of Mathematicians. The HLF should, of course, take advantage of that quadrennial opportunity to get its message out.

The small turnout of mathematics laureates was only a small blot on an otherwise spectacularly successful meeting. Atiyah's “Advice to a Young Mathematician" address contained a number of points that the young researchers were talking about all week. For example, "Good ideas come from bad lectures," Atiyah said. "If the speaker's proof is terrible, you should start asking yourself, is there a better way?" Voevodsky delivered an inspiring explanation of his research on "univalent foundations of mathematics"-a subject that should be of interest to computer scientists, as it relates to computer verification of proofs. In many lectures, the laureates showed that they are not afraid to venture beyond their original expertise. Witness Voevodsky moving from topology to type theory, or Smale moving from dynamical systems to the protein folding problem.

The formal lectures were only part, and arguably not even the most important part, of the forum. The week offered many chances for social interaction: banquets at the Schwetzingen Castle and Heidelberg Castle, a free biergarten, a long combination boat ride and dinner on the Neckar River. The boat ride seemed to be particularly successful for social interaction, as the laureates and young researchers were sitting literally elbow to elbow for several hours, with no way off the boat and no choice but to mingle!

I'll leave the final word on the forum to the participants, some of whom I contacted by email after returning home.

The students present were the most impressive bunch I have seen assembled anywhere. [They] had a wide perspective with depth, of science in general. I certainly enjoyed my exchanges with them, from Brazil, from Pakistan, from Iran, etc. -Stephen Smale, Fields Medal laureate

I had many wonderful conversations that included common problems we face as a young researcher, such as how do you balance family life, social life, dating and work? How do you gauge progress? Why do you want to be a researcher?... The few researchers I met that didn't enjoy the HLF seemed to approach it the wrong way. They expected it to be a research conference and wanted very specialized, technical 


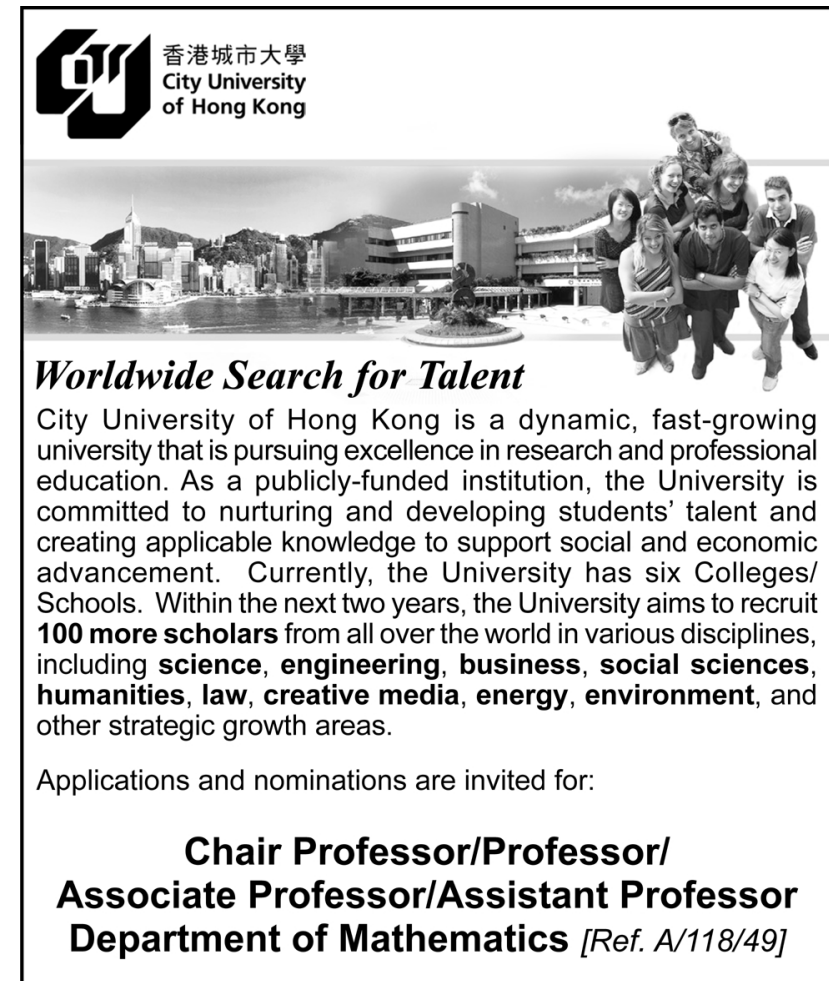

Duties : Conduct research in areas of Applied Mathematics including Analysis and Applications, Mathematical Modelling (including biological/physical/financial problems), Scientific Computation and Numerical Analysis, and Probability and Statistics; teach undergraduate and postgraduate courses; supervise research students; and perform any other duties as assigned.

Requirements : APhD in Mathematics/Applied Mathematics/ Statistics with an excellent research record.

\section{Salary and Conditions of Service}

Remuneration package will be driven by market competitiveness and individual performance. Excellent fringe benefits include gratuity, leave, medical and dental schemes, and relocation assistance (where applicable). Initial appointment will be made on a fixed-term contract.

\section{Information and Application}

Further information on the posts and the University is available at http://www.cityu.edu.hk, or from the Human Resources Office, City University of Hong Kong, Tat Chee Avenue, Kowloon Tong, Hong Kong [Email : hrojob@cityu.edu.hk/Fax : (852) 27881154 or (852) 3442 0311].

Please send the nomination or application with a current curriculum vitae to Human Resources Office. Applications and nominations will receive full consideration until the positions are filled and only shortlisted applicants will be contacted. Please quote the reference number in the application. Shortlisted candidates for the post of Assistant Professor will be requested to arrange for at least 3 reference reports sent directly by their referees to the Department, specifying the position applied for. The University's privacy policy is available on the homepage.

The University also offers a number of visiting positions through its "CityU International Transition Team" scheme for current graduate students, postdoctoral scholars, and for early-stage and established scholars, as described at http://www.cityu.edu.hk/provost/cityu_international_transition.htm.

City University of Hong Kong is an equal opportunity employer and we are committed to the principle of diversity. We encourage applications from all qualified candidates, especially those who will enhance the diversity of our staff. talks by the laureates in their field. -Kevin Hughes, young researcher, University of Edinburgh

The Heidelberg Laureate Forum was definitely the experience of a lifetime for a student like me....[P]articularly inspiring was the workshop on work-life balance. I had expected it to only be student researchers and was surprised when Avi Wigderson came in and sat down next to me. -Irene Rae, young researcher, University of Wisconsin

What I liked most about HLF was the opportunity to talk to the laureates and find out a bit more about their personal journeys, to have them listen to me and treat me like a person.... Giving young researchers the opportunity to speak as well would have been great." -Philip Asare, young researcher, University of Virginia

Although no official announcement has been made at the time of this writing, all signs are that the meeting of dreams will convene again in 2014. Klaus Tschira confirmed that he definitely wants to hold another one next year and to invite both mathematicians and computer scientists again. Says Tschira, "We'll make some improvements next year, because we're still on a learning curve, but for the first try, we did pretty well." 